\title{
Divercin V41, a new bacteriocin with two disulphide bonds produced by Carnobacterium divergens V41: primary structure and genomic organization
}

\author{
Anita Métivier, ${ }^{1,2}$ Marie-France Pilet, ${ }^{1}$ Xavier Dousset, ${ }^{1}$ Odile Sorokine, ${ }^{3}$ \\ Patricia Anglade, ${ }^{4}$ Monique Zagorec, ${ }^{4}$ Jean-Christophe Piard, ${ }^{4}$ \\ Didier Marion, ${ }^{5}$ Yves Cenatiempo ${ }^{2}$ and Christophe Fremaux ${ }^{2,6}$
}

Author for correspondence: Christophe Fremaux. Tel: +335494540 06. Fax: +33549453503. e-mail: christophe.fremaux@cri.univ-poitiers.fr

1 ENITIAA, Laboratoire de Microbiologie, 44072 Nantes Cedex, France

2 Institut de Biologie Moléculaire et d'Ingénierie Génétique, CNRS-ESA 6031, Université de Poitiers, 40 avenue du Recteur Pineau, 86022 Poitiers Cedex, France

3 CNRS, Laboratoire de Spectrométrie de Masse Bioorganique, URA31 Université Louis Pasteur, 67008 Strasbourg, France

4 INRA, Domaine de Vilvert, 78352 Jouy en Josas cedex, France

5 INRA, Unité de Biochimie et Technologie des Protéines, 44316 Nantes cedex, France

6 Texel, groupe RhónePoulenc, ZA de Buxières BP 10, 86220 Dangé Saint-Romain, France
Divercin V41 is a new bacteriocin produced by Carnobacterium divergens V41, a lactic acid bacterium isolated from fish viscera. The amino acid sequence of divercin V41 showed high homologies with pediocin PA-1 and enterocin A. Two disulphide bonds were present in the hydrophilic $\mathrm{N}$-terminal domain and in the highly variable hydrophobic C-terminal domain, respectively. A DNA probe designed from the $\mathbf{N}$-terminal sequence of the purified peptide was used to locate the structural gene of divercin V41. A $6 \mathrm{~kb}$ chromosomal fragment containing the divercin $\mathbf{V 4 1}$ structural gene (dvnA) was cloned and sequenced. The results indicate that divercin V41 is synthesized as a pre-bacteriocin of 66 amino acids. The 23-residue $\mathrm{N}$-terminal extension is cleaved off to yield the mature 43-amino-acid divercin V41. In addition, the fragment encodes putative proteins commonly found within bacteriocin operons, including an ATPdependent transporter, two immunity-like proteins and the two components of a lantibiotic-type signal-transducing system. The genetic organization of the fragment suggested important gene rearrangements.

Keywords: bacteriocin, Carnobacterium, lactic acid bacteria, anti-Listeria

\section{INTRODUCTION}

Lactic acid bacteria (LAB) are extensively used in fermented foods not only to improve their flavour and texture, but also to extend their shelf-life. Many LAB are capable of inhibiting growth of some Gram-positive bacteria and pathogenic species such as Listeria monocytogenes, by secreting different antimicrobial compounds, including peptides and proteins. These proteinaceous molecules, also called bacteriocins, have promising potential as food grade preservatives to

Abbreviations: $A U$, activity units; HPK, histidine protein kinase; $L A B$, lactic acid bacteria; RR, response regulator; TFA, trifluoroacetic acid.

The EMBL accession number for the sequence reported in this paper is AJ224003. increase safety of fermented products. The great structural diversity of LAB bacteriocins (Klaenhammer, 1993; Jack et al., 1995) is an opportunity to overcome the problems of resistance, which generally occur with a single bacteriocin, and also provides biotechnologists with different models for the design of new antimicrobial peptides. Among bacteriocin peptides, lantibiotics have been extensively studied and are used as preservatives in some food products (Schillinger et al., 1996). These bacteriocins contain modified amino acid residues, lanthionine and methyllanthionine, which are formed post-translationally (de Vos et al., 1995). Another group of peptides which do not have a modified amino acid residue form a subclass of peptides called the antiListeria bacteriocins, class IIa bacteriocins (Klaenhammer, 1993) or cystibiotics (Jack et al., 1995). It 
includes sakacin A and $\mathrm{P}$ produced by Lactobacillus sakei (Holck et al., 1992; Tichaczek et al., 1992), leucocin A-UAL 187 produced by Leuconostoc gelidum UAL187 (Hastings \& Stiles, 1991), mesentericin Y105 produced by Leuconostoc mesenteroides Y105 (Héchard et al., 1992), carnobacteriocins BM1, B2 and piscicocin V1a produced by Carnobacterium piscicola (Quadri et al., 1994; Bhugaloo-Vial et al., 1996) and enterocin A produced by Enterococcus faecium (Aymerich et al., 1996). These peptides share structural homologies and are composed of a conserved $\mathrm{N}$-terminal hydrophilic domain and a highly variable C-terminal hydrophobic domain. Based on recent studies with nisin, pediocin PA-1 and lactococcin A, these peptides act by pore formation in the cytoplasmic membrane and consecutive dissipation of protonmotive force (van Belkum et al., 1991; Bruno \& Montville, 1993).

Analysis of the genetic determinants of several class IIa bacteriocins revealed that genes involved in production, transport of the bacteriocin and immunity are organized in one or two operon-like structures. Pediocin PA-1, lactococcin A, sakacin A and sakacin P operons possess at least two genes that encode proteins homologous to $\mathrm{ABC}$-transporters and accessory proteins probably involved in the transport of class IIa bacteriocins (Marugg et al., 1992; Stoddard et al., 1992; Axelsson \& Holck, 1995; Hühne et al., 1996).

As only a limited number of anti-Listeria bacteriocins from fish LAB had been described, Pilet et al. (1995) looked for such substances. They isolated two producer strains from fish, namely C. piscicola V1 and Carnobacterium divergens $\mathrm{V} 41$. C. piscicola $\mathrm{V} 1$ produces two distinct anti-Listeria bacteriocins, piscicocin V1a and piscicocin V1b (Bhugaloo-Vial et al., 1996). Here we report on the purification and biochemical and genetic characterization of divercin V41, a new class IIa bacteriocin produced by $C$. divergens V41.

\section{METHODS}

Bacterial strains and media. The bacteriocin producer $C$. divergens V41 was isolated from fish viscera (Pilet et al., 1995). In the assay for bacteriocin activity, C. piscicola NCDO 2762 (Pilet et al., 1995) was used as indicator strain. Carnobacteria were grown in Elliker broth (Biokar Diagnostics). Escherichia coli DH5 $\alpha$ (Gibco-BRL) was propagated in LB broth or on agar $\left(15 \mathrm{~g} \mathrm{l}^{-1}\right)$ at $37^{\circ} \mathrm{C}$ (Sambrook et al., 1989). Ampicillin, erythromycin, IPTG and X-Gal were used at concentrations of $100,150,80$ and $80 \mu \mathrm{g} \mathrm{ml}^{-1}$, respectively. All the strains were stored as frozen stocks at $-20^{\circ} \mathrm{C}$ in media containing $15 \%$ (v/v) glycerol.

Bacteriocin production and assay. C. divergens V41 was inoculated $(2 \%, v / v)$ in Tween-deficient MRS broth (prepared from basal ingredients; De Man et al., 1960) and grown at $20^{\circ} \mathrm{C}$ for $42 \mathrm{~h}$. Culture $\mathrm{pH}$ was maintained at 6.5 using $6 \mathrm{M}$ $\mathrm{NaOH}$ as neutralizer. After centrifugation ( $30 \mathrm{~min}, 12000 \mathrm{~g}$ ), active supernatant was filtered successively through 0.8 and $0.22 \mu \mathrm{m}$ pore-size filters and treated for $10 \mathrm{~min}$ at $100^{\circ} \mathrm{C}$ to inactivate proteases. Active supernatants were stored at $-20^{\circ} \mathrm{C}$. Bacteriocin activity was assayed as described previously by spot-on-lawn inhibition tests and expressed in arbitrary activity units (AU) (Pilet et al., 1995).

\section{Purification of divercin V41}

Ammonium sulphate precipitation. Cell-free supernatants were treated with ammonium sulphate at $50 \%(\mathrm{w} / \mathrm{v})$ saturation. The mixture was stirred at $4^{\circ} \mathrm{C}$ for $4 \mathrm{~h}$ and centrifuged $(1 \mathrm{~h}$, $20000 \mathrm{~g}$ ). The pellets were dispersed in $25 \mathrm{mM}$ ammonium acetate buffer at $\mathrm{pH} 6.5$. Protein content was determined as described by Scopes (1988).

Purification by reversed-phase chromatography. The ammonium precipitate was loaded on a $\mathrm{C}_{18}$ Sep-Pack reversed-phase cartridge (Waters Millipore) and washed with $40 \%$ (v/v) 2propanol in $25 \mathrm{mM}$ ammonium acetate, $\mathrm{pH} 6.5$. The bacteriocin was eluted using $60 \%(\mathrm{v} / \mathrm{v})$ 2-propanol in the same buffer. After drying under vacuum (Speed-Vac; Savant), bacteriocin-containing fractions were diluted in $0.1 \%$ trifluoroacetic acid (TFA). Since this treatment did not allow complete dissolution of the extract, the insoluble material was pelleted by centrifugation $(5 \mathrm{~min}, 11500 \mathrm{~g})$. The resulting pellet was dissolved in $0 \cdot 1 \%$ TFA containing $6 \mathrm{M}$ urea and this extract was used further for final purification by the $C_{18}$ reversed-phase HPLC system (LDC CM4000; Milton Roy). Active fractions $(200 \mu \mathrm{l})$ were loaded on a $C_{18}$ Nucleosyl column $(250 \times 4.6 \mathrm{~mm})$. Elution was performed at a flow rate of $1 \mathrm{ml} \mathrm{min}-1$ using a linear gradient from $100 \%$ solvent A $(0.1 \%, v / v$, TFA $)$ to $100 \%$ solvent $\mathrm{B}(90 \%$ acetonitrile in $0.1 \%$ TFA, v/v) within $55 \mathrm{~min}$. Peptide fractions were detected spectrophotometrically by measuring the $A_{220}$ (LDC Analytical) and collected manually. The fractions were dried under reduced pressure, dissolved in $1 \mathrm{ml}$ deionized water and assayed for both bacteriocin activity and protein content.

Amino acid sequencing, enzymic cleavage and MS of divercin V41. Amino acid sequencing was performed by Edman degradation on an automatic sequencer (model 477; Applied Biosystems). Cysteine residues were identified after reduction and alkylation using 4-vinylpyridine. Cleavage of divercin V41 by Asp- $\mathrm{N}$ (Boehringer Mannheim) was performed in $50 \mathrm{mM}$ Tris/ $\mathrm{HCl}(\mathrm{pH} 8)$ for $14 \mathrm{~h}$ at $30^{\circ} \mathrm{C}$ using $1 / 50(\mathrm{w} / \mathrm{w})$ enzyme to substrate. The hydrolysis product was applied on a reversed-phase $\mathrm{C}_{18}$ column (Merck RP18) and the resulting peptides were separated using a gradient of $100 \%$ solvent $A$ to $50 \%$ solvent $B(v / v)$ within $50 \mathrm{~min}$. The amino acid sequence of the two isolated peptides was obtained as described above.

Mass measurement was performed using electrospray MS on a VG Bio-Q quadrupole with a mass range of $4000 \mathrm{Da}$ (BioTech) in the positive mode. The peptide was dissolved in $\mathrm{H}_{2} \mathrm{O} / \mathrm{CH}_{3} \mathrm{CN}(50 / 50, \mathrm{v} / \mathrm{v}) ; 10 \mu \mathrm{l}$ aliquots were then introduced into the ion source at a flow rate of $4 \mu \mathrm{min}^{-1}$. Scanning was performed from $\mathrm{m} / z 500$ to $\mathrm{m} / z 1500$ in $10 \mathrm{~s}$ with the resolution adjusted so that the peak at $m / z 998$ from horseheart myoglobin was $1.5-2$ wide on the base. Calibration was performed using the multiply charged ions produced by separate introduction of horse-heart myoglobin (16954.4 Da) (Jaquinod et al., 1993).

DNA methodologies. Plasmids from E. coli and LAB were extracted and purified as previously described by Sambrook $e t$ al. (1989) and Muriana \& Klaenhammer (1987), respectively. Plasmid DNA was digested with restriction enzymes (Gibco$\mathrm{BRL}$ ). Analytical and preparative agarose gel electrophoresis 
in TBE (89 mM Tris-borate, pH 8.3, 2 mM EDTA) were done as described by Sambrook et al. (1989). Purified DNA restriction fragments were obtained by using the Prep-A-Gene kit (Bio-Rad). T4 DNA ligase (Gibco-BRL) was used for the DNA ligation. Competent $E$. coli cells were prepared and transformed according to the method of Hanahan (1983). Colony hybridization and Southern blot hybridization were performed as described by Sambrook et al. (1989) using Hybond- + nylon membranes (Amersham). Oligonucleotides were labelled by using $\mathrm{T} 4$ polynucleotide kinase (Gibco-BRL) and $\left[\gamma_{-}{ }^{32} \mathrm{P}\right] \mathrm{ATP}\left(100 \mathrm{TBq} \mathrm{mmol}^{-1}\right.$; Amersham Life Science) according to the supplier's recommendations. Double-stranded DNA probe was obtained by random priming (Sambrook et al., 1989) using $\left[\alpha^{-32} \mathrm{P}\right] \mathrm{dCTP}(220 \mathrm{TBq}$ $\mathrm{mmol}^{-1}$; Amersham Life Science). Sequencing, based on the chain-termination method (Sanger et al., 1977), was done with the Auto-read sequencing kit (Pharmacia) using either standard or specific primers with an automated DNA sequencer (ALF, Pharmacia). DNA or protein homology searches (GenBank, EMBL and SWISS-PROT) and sequence analysis were performed with the programs of the GCG sequence analysis software package (University of Wisconsin).

PCR. To verify the $d v n T 1 / d v n T 2$ gene fusion, this region was amplified by PCR using primers DVND1, 5'-AGA-TGAGGT-GAC-AAG-CC-3', and DVND2, 5'-GCA-TCT-AATTTT-GGA-GAC-C-3', deduced from the pRID6 nucleotide sequence. Amplifications were carried out with Taq DNA polymerase (Perkin Elmer-Cetus) according to the supplier's recommendations and using the Gene Ataq thermocycler (Pharmacia) under the following conditions: 35 cycles of denaturation at $94{ }^{\circ} \mathrm{C}$ for $10 \mathrm{~s}$, annealing at $48^{\circ} \mathrm{C}$ for $10 \mathrm{~s}$ and elongation at $72^{\circ} \mathrm{C}$ for $20 \mathrm{~s}$; and one further cycle of elongation at $72^{\circ} \mathrm{C}$ for $2 \mathrm{~min}$.

\section{RESULTS}

\section{Purification of divercin V41}

C. divergens $\mathrm{V} 41$ was grown to stationary phase in Tween-deficient MRS broth at $20^{\circ} \mathrm{C}$ under controlled $\mathrm{pH}$ conditions to allow the production of the bacteriocin. Ammonium sulphate precipitation, at $50 \%$ saturation, of the cell-free culture supernatant removed $98 \%$ of the contaminating proteins (Table 1). After this treatment, total inhibitory activity recovered in the

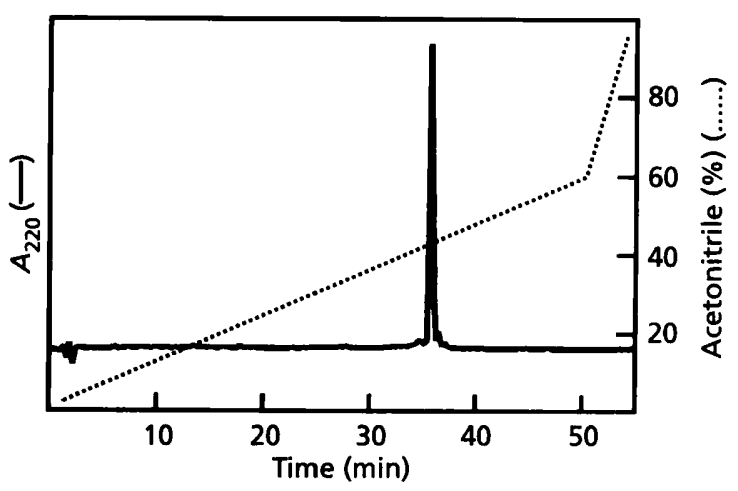

Fig. 1. Reversed-phase chromatography on a $C_{18}$ Nucleosyl column of the urea/TFA-solubilized fraction obtained from $C_{18}$ Sep-Pack cartridge chromatography.

pellet increased by 122 -fold. Further purification of divercin V41 using $\mathrm{C}_{18}$ Sep-Pack cartridges provided an extract which could not be entirely solubilized in $0.1 \%$ TFA. Treatment of the insoluble material with $0 \cdot 1 \%$ TFA/6 $M$ urea successfully solubilized the remaining peptide material. The recovered activity of divercin V41 again dramatically increased by $10^{4}$-fold upon this purification step, while an additional $99 \%$ of contaminating proteins were eliminated (Table 1). Final purification of divercin V41 was achieved by submitting the urea/TFA-solubilized fraction to reversed-phase $C_{18}$ HPLC. The elution profile monitored at $220 \mathrm{~nm}$ revealed a single absorbency peak eluting with $45 \%$ acetonitrile (Fig. 1) and correlating bactericidal activity as determined by spot-on-lawn inhibition tests against $C$. piscicola NCDO 2762 (not shown). The specific activity of the purified divercin V41 was therefore calculated to

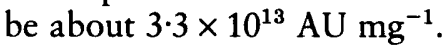

\section{Amino acid sequence of divercin V41}

Amino acid sequencing of divercin V41 enabled determination of the first 20 amino acid residues, including two blank cycles, and identified an aspartic acid residue at position 18. The enzymic cleavage of divercin V41 with Asp- $\mathrm{N}$ endoproteinase yielded two peptides (pep-

Table 1. Purification of divercin V41 from C. divergens V41

\begin{tabular}{|lccc|}
\hline Sample $(\mathrm{ml})$ & $\begin{array}{c}\text { Total protein } \\
(\mathbf{m g})^{*}\end{array}$ & $\begin{array}{c}\text { Total activity } \\
(\mathrm{AU}) \dagger\end{array}$ & $\begin{array}{c}\text { Increase in } \\
\text { total activity } \\
\text { (-fold) }\end{array}$ \\
\hline I. Culture supernatant $(20)$ & $445 \cdot 4$ & $8.2 \times 10^{5}$ & - \\
II. $50 \%\left(\mathrm{NH}_{4}\right)_{2} \mathrm{SO}_{4}$ precipitate $(2)$ & $8 \cdot 2$ & $10^{8}$ & 122 \\
III. $\mathrm{C}_{18}$ Sep-Pack cartridge $(0 \cdot 2)$ & $6 \cdot 2 \times 10^{-2}$ & $10^{12}$ & 10000 \\
IV. $\mathrm{C}_{18}$ reversed-phase HPLC $(0 \cdot 5)$ & $3 \times 10^{-2}$ & $10^{12}$ & 0 \\
\hline
\end{tabular}

* Protein content was estimated by measuring the $A_{210}$ as described by Scopes (1988).

† Bacteriocin total activity (AU) was determined against C. piscicola NCDO 2762 as described by Pilet et al. (1995). 


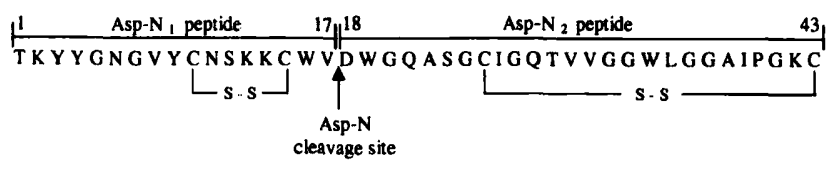

Fig. 2. Amino acid sequence of the purified divercin V41 obtained from sequencing of the native protein and of the two peptides originating from the cleavage of the native peptide by Asp-N. The four cysteine residues were identified after the reduction and alkylation of the peptide. The two disulphide bonds are indicated as concluded from Asp-N cleavage.

tides Asp- $\mathrm{N}_{1}$ and Asp- $\mathrm{N}_{2}$ ) (Fig. 2) that were separated on a reversed-phase $\mathrm{C}_{18}$ column. Sequencing of the Asp$\mathrm{N}_{1}$ peptide (17 residues) confirmed the $\mathrm{N}$-terminal sequence of divercin V41. Sequencing of the Asp- $\mathrm{N}_{2}$ peptide ( 26 residues) confirmed the amino acid residues in positions 18, 19 and 20 and completed the sequence of divercin V41 (Fig. 2). Two additional blank cycles were encountered in the sequencing of Asp- $\mathrm{N}_{2}$.

The amino acid composition of the purified peptide (data not shown) revealed the presence of four cysteines in the primary structure of divercin V41. Thus, it was likely that the four blank cycles obtained in the sequencing of Asp- $\mathrm{N}_{1}$ and Asp- $\mathrm{N}_{2}$ peptides corresponded to cysteine residues. To verify this hypothesis, reduction and alkylation of the bacteriocin with 4vinylpyridine was performed, and this led to the identification of four alkylated cysteine residues in positions 10,15, 25 and 43. Conclusively, the sequence of divercin V41 corresponded to a 43-amino-acid peptide with a calculated molecular mass of $4513 \mathrm{Da}$. Ionspray MS gave a molecular mass of $4509 \mathrm{Da}$ for divercin V41, suggesting the presence of two disulphide bonds within the purified bacteriocin. Because the enzymic cleavage provides the two peptides Asp- $\mathrm{N}_{1}$ and Asp- $\mathrm{N}_{2}$ under non-reducing conditions, the disulphide bonds must be internal to each of the Asp-N peptides. Therefore, the cysteine bridges in divercin V41 were assigned to $\mathrm{Cys}_{10}-\mathrm{Cys}_{15}$ and $\mathrm{Cys}_{25}-\mathrm{Cys}_{43}$ (Fig. 2).

\section{Cloning of the divercin V41 locus}

A degenerate 23-mer oligonucleotide, termed Pdvn $\left(5^{\prime}\right.$ AAG/A-TAC/T-TAC/T-GGC/G/T/A-AAC/TGGC/G/T/A-GTC/G/T/A-TA), was designed according to the amino acid sequence of the purified divercin V41 and used as a probe in Southern blot hybridizations. On plasmid extracts, these analyses revealed a hybridization signal with contaminant chromosomal DNA but did not reveal any plasmid band (not shown). Thus, the divercin V41 structural gene was likely to be chromosomally encoded.

With total DNA extracted from C. divergens V41 and digested with EcoRI, HindIII and EcoRV, hybridizations revealed fragments of approximately $6.0,4.0$ and $3.9 \mathrm{~kb}$, respectively. A restricted genomic library was generated in E. coli $\mathrm{DH} 5 \alpha$ by ligating EcoRI restriction fragments of about $6.0 \mathrm{~kb}$, generated from C. divergens V41 DNA, into the EcoRI-linearized pBluescript II $\mathrm{KS}(+)$ cloning vector (Stratagene). The library was then screened with the labelled Pdvn probe and a clone containing the plasmid pRID6 was isolated. The plasmid pRID6 was found to contain a $6.0 \mathrm{~kb} E c o R I$ fragment and the presence of the divercin V41 structural gene was demonstrated by nucleotide sequence analysis.

\section{Nucleotide sequence analysis of the divercin V41 locus}

The complete DNA sequence of the $6.0 \mathrm{~kb} E c o \mathrm{RI}$ fragment was determined on pRID6 and analysed (Fig. 3). Nucleotide sequence databases (EMBL, GenBank) did not display any sequence homologous to that of the divercin V41 locus. Sequence analysis revealed four complete ORFs, $d v n A, d v n T 1 / T 2, d v n I$ and $d v n R$, in addition to two truncated ORFs (orfA and $d v n K$ ) located on both sides of the cloned fragment. All of the ORFs were located on the same DNA strand and were preceded by a putative RBS with an appropriate spacing between the RBS and the initiation codon. The $5^{\prime}$ end of $d \nu n K$ slightly overlapped the end of $d \nu n R$. Further investigation of a large intergenic region located in-

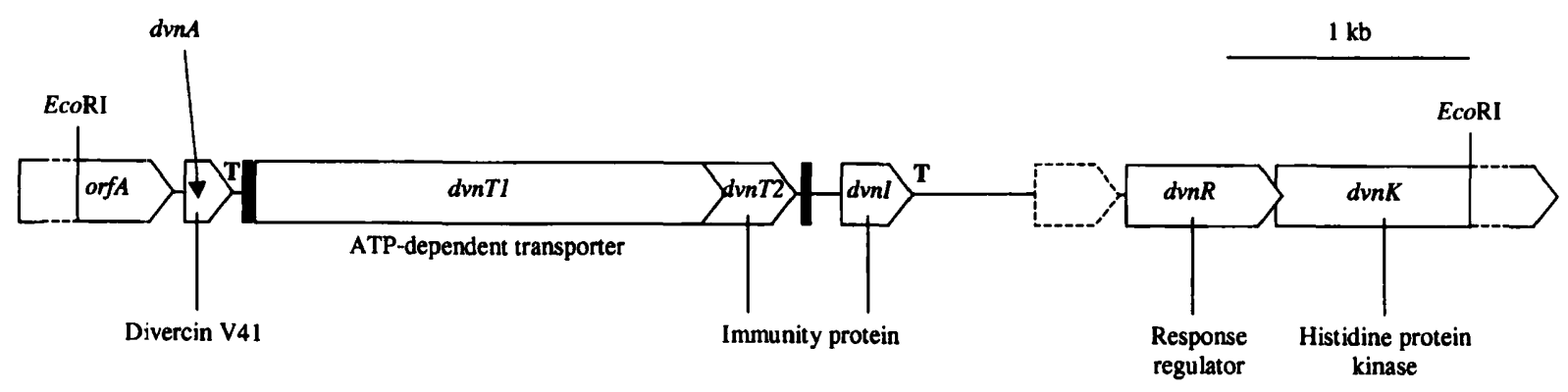

Fig. 3. Schematic overview of the genetic organization of the EcoRI chromosomal fragment encoding divercin V41. Arrowed boxes represent putative genes (orfA, dvnA, dvnT1, dvnT2, dvnR and $d v n K$ ) and their respective orientation. The putative functions of the proteins deduced from the genes are indicated. The box in dashed lines represents an ORF that lacks typical translation initiation signals and whose product resembles the C-terminus of an ATP-dependent transporter. $T$, Sequences resembling rho-independent terminators. The thin black boxes indicate duplicated sequences surrounding dvnT1/T2. 
between $d v n I$ and $d v n R$ displayed an ORF lacking transcriptional and translational signals (Fig. 3). Analysis of the protein deduced from this ORF revealed a high degree of identity with the C-terminus of ATP-dependent translocators of various bacteriocins. Two regions of dyad symmetry were found. One was downstream of $d \nu n A$ with a calculated free energy $\left(\Delta G_{0}\right)$ of $-17.0 \mathrm{kcal}(-71.4 \mathrm{~kJ})$, representing a putative rhoindependent terminator. The second has a $\Delta G_{0}$ of $-13.7 \mathrm{kcal}(-57.5 \mathrm{~kJ})$ and was located between $d v n \mathrm{I}$ and $d v n R$ within a large non-coding region (positions 3641-4549). In addition, a duplicated sequence of 23 nucleotides (TTATNTTATGAATATNTATTAGT) was found on both sides of $d v n T 1 / T 2$.

\section{Deduced protein analyses}

The first ORF (named orf $A$ ) encodes a putative truncated protein of at least 127 amino acid residues. Comparison of its sequence with those in the databases did not reveal any significant homology with previously described sequences. Analysis of this sequence revealed the presence of a hydrophobic C-terminal region that was predicted to form a transmembrane helix, thus suggesting that the protein was anchored within the cytoplasmic membrane.

The second ORF (designated $d \nu n A$ ) encodes a protein of 66 amino acids. Comparison of this sequence with the sequence of the mature divercin V41 showed that $d \nu n A$ was the bacteriocin structural gene and that the bacteriocin was synthesized as a prepeptide consisting of a 43-residue C-terminal peptide matching the amino acid sequence of the purified divercin V41 and a 23-residue $\mathrm{N}$-terminal extension. This defined the cleavage site for the N-terminal extension behind a glycine-glycine sequence.

The third ORF (designated $d v n T 1 / T 2$ ) predicts a protein (DvnT) of 819 amino acids. The predicted DvnT consists of a large, mostly hydrophobic, core containing six putative transmembrane helices surrounded by two conserved domains. A 150 -amino-acid $\mathrm{N}$-terminal domain presents similarities to the N-terminus of ATPdependent transporters, especially the conserved cysteine and histidine motif described by Nes et al. (1996). The 270-amino-acid C-terminal domain contains the conserved A and B sites (Axelsson \& Holck, 1995; Fremaux et al., 1995), sequences involved in ATP binding and hydrolysis (Fath \& Kolter, 1993). Thus, searches for sequence homologies revealed that DvnT is an ATP-dependent transporter that belongs to the Hly family of membrane translocators (Higgins et al., 1986). Best similarity scores ranging from 49.9 to $64.5 \%$ were obtained with the ATP-dependent transporters PlnG, SapT, LcnC, MesD, LcaD, SppT and PedD, which are dedicated to the export of the following, respectively: plantaricin A (Diep et al., 1996), sakacin A (Axelsson \& Holck, 1995), lactococcin A (Stoddard et al., 1992), mesentericin Y105 (Fremaux et al., 1995), leucocin A (van Belkum \& Stiles, 1995), sakacin P (Hühne et al., 1996) and pediocin PA-1 (Venema et al., 1995). How- ever, DvnT diverges from all these bacteriocin transporters at its C-terminus. Indeed, DvnT presented a 104amino-acid extension. Careful analyses of the nucleotide region corresponding to the beginning of this extension revealed the presence of a start codon preceded at the appropriate distance by a typical RBS sequence. This suggested that $d \nu n T 1 / T 2$ results from the fusion of two distinct ORFs hereafter designated $d \nu n T 1$ and $d v n T 2$. Since mutations and/or DNA rearrangements could occur during the various cloning steps and strain propagation, PCR was initially used to amplify chromosomal DNA extracts of $C$. divergens V41 and to clone the $d v n T 1 / T 2$ fusion region. Several independent clones were sequenced and the initial sequence was confirmed. Database searches revealed similarities between DvnT2 (the protein deduced from $d v n T 2$ ) and the carnobacteriocin BM1 immunity protein (Quadri et al., 1994), suggesting therefore that DvnT2 is the divercin V41 immunity protein.

However, the fourth ORF (called $d v n I$ ) was found to encode a putative protein highly homologous to MesI, LcaB and ORF2-EntA, the best score being obtained for ORF2-EntA $(52.6 \%$ identity, $17.5 \%$ similarity). The involvement of MesI, LcaB and ORF2-EntA in the immunity to the bacteriocins mesentericin Y105, leucocin A and enterocin A, respectively, has been unambiguously demonstrated (Fremaux et al., 1995; van Belkum \& Stiles, 1995; Aymerich et al., 1996); this suggests that DvnI is another divercin V41 immunity protein.

The protein deduced from the fifth ORF (designated $d \nu n R$ ) showed high similarity to SpaR ( $47 \%$ identity) and NisR (23\%), two response regulators (RRs) involved in the regulation of the production of the lantibiotics subtilisin and nisin, respectively (Entian $\&$ de Vos, 1996). Gene $d v n R$ was closely associated in an operon-like structure with the sixth ORF (designated $d v n K)$. The start codon of $d v n K$ overlapped the last codons of $d \nu n R$. A similar genetic organization was observed for the subtilisin and nisin operons, in which $s p a K$ and nisK, respectively, encoded histidine protein kinases (HPKs). HPKs associated with their corresponding RRs constitute two-component signal-transducing systems (Hoch \& Silhavy, 1995). The protein deduced from $d u n K$ (which probably extends over the EcoRI cloning site) was found to be poorly homologous to SpaK and NisK. However, in common with all of the HPKs, DvnK contained two putative membrane-spanning segments (positions 16-36 and 148-166) as well as a conserved histidine residue (position 241) corresponding to a functional site of phosphorylation. Thus, $d v n K$ is likely to encode an HPK.

\section{DISCUSSION}

Purification of divercin V41 from culture supernatant of C. divergens V41 was achieved using a procedure that included ammonium sulphate precipitation and reversed-phase chromatography. Unlike what has been observed for other bacteriocins, the purification of 


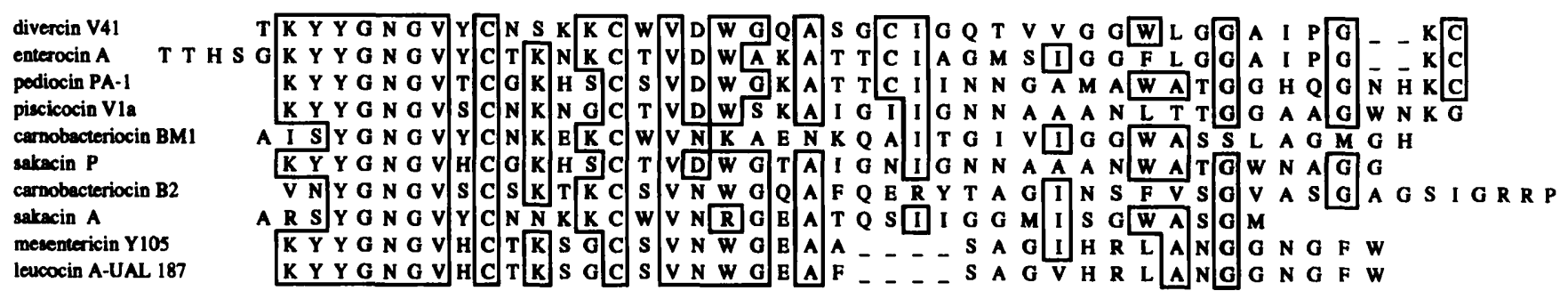

Fig. 4. Primary sequence of divercin V41 aligned with the sequences of other anti-Listeria bacteriocins. Highly conserved residues are boxed. Sequences were obtained from Aymerich et al. (1996) (enterocin A); Marugg et al. (1992) (pediocin PA-1); Bhugaloo-Vial et al. (1996) (piscicocin V1a); Quadri et al. (1994) (carnobacteriocins BM1 and B2); Holck et al. (1992) (sakacin A); Tichaczek et al. (1992) (sakacin P); Hastings \& Stiles (1991) (leucocin A-UAL 187); and Héchard et al. (1992) (mesentericin Y105).

divercin V41 results in a phenomenal increase in the total amount of bacteriocin recovered. First, ammonium sulphate precipitation of divercin V41 led to a significant increase (122-fold) in the total bacteriocin activity. Although this phenomenon has already been observed with other bacteriocins (Muriana \& Klaenhammer, 1991; Piard et al., 1992; Jimenez-Diaz et al., 1993), it is still not explained. Possibly, some compounds inhibitory to the bacteriocin activity may be removed upon ammonium sulphate precipitation. Similarly, a dramatic increase (10000-fold) of total recovered activity occurred following the second purification step. Interestingly, divercin V41 shows a propensity to form aggregating complexes after elution from Sep-Pack cartridges and dissociation of those aggregates required high amounts of urea. The dissociation of bacteriocin complexes may explain the very high final yield. This feature has also been reported for the purification of leucocin A (Hastings et al., 1991).

The class IIa bacteriocins from LAB contain a highly conserved $\mathrm{N}$-terminal hydrophilic domain and a highly variable hydrophobic domain (Fig. 4). Divercin V41 shares the greatest homology with pediocin PA-1 and enterocin $\mathrm{A}$, with the presence of four cysteine residues forming two disulphide bridges, whereas the others only have two cysteine residues. Although the exact structure-function relationship regarding the cysteine content of bacteriocins is not yet fully understood, it does appear that a higher number of cysteine residues correlates with a wider activity spectrum of bacteriocins. In addition, preliminary studies suggest that the thioester linkage in class IIa bacteriocins, containing more than one disulphide bridge, may be necessary for their antibacterial activity (Chikindas et al., 1993). It is also interesting to note that divercin V41 has three tryptophan residues with two of these residues in the $\mathrm{N}$ terminal conserved domain. As previously discussed, these residues could be important for insertion in membranes (Bhugaloo-Vial et al., 1996).

A $6.0 \mathrm{~kb}$ EcoRI restriction fragment from the chromosome of $C$. divergens that contains the divercin V41 structural gene was cloned and analysed. The characterization of the $d \nu n A$ structural gene allowed us to identify a 23-residue extension at the $\mathrm{N}$-terminus of divercin V41. This sequence is quite different from typical signal sequences since it is devoid of a core hydrophobic domain (von Heijne, 1990). With the exception of divergicin $\mathrm{A}$, produced by $C$. divergens, which is synthesized along with a Sec-dependent signal sequence (Worobo et al., 1995), the same kind of leader peptide has been found in most pre-bacteriocins (Jack et al., 1995). Alignment of some leader peptides shows a high conservation in the hydrophobicity and charges of individual amino acid residues (data not shown). Hydrophobic residues are found at positions $-4,-7,-12$ and -15 ; hydrophilic residues are present at positions $-8,-9$ and -11 , and a conserved processing site of two glycine residues is found at positions -2 and -1 (Håvarstein et al., 1994). These features suggest the involvement of a dedicated secretion machinery for those bacteriocins. Dedicated secretion machineries for bacteriocins described so far are defined as ABCtransporters (Stoddard et al., 1992) and involve two distinct proteins, an ATP-dependent translocator and an accessory factor. Usually, these proteins are encoded within an operon closely associated with the bacteriocin genes (Nes et al., 1996). Within the divercin V41 locus, dvnT1 encodes a putative ATP-dependent translocator that may be involved in the transport of divercin V41. However, no gene encoding an accessory factor was found within the cloned fragment, suggesting that the genetic organization of the locus may be unusual. Several immunity proteins and immunity genes have been characterized (Nes et al., 1996). These immunity proteins do not usually share large homologies among each other and a bacteriocin always has a single immunity protein associated. In addition, in all cases, the bacteriocin gene precedes the immunity gene within a small operon. Such genetic organization seems to be common to all the class II bacteriocins (Nes et al., 1996). However, a putative terminator was found downstream of $d v n A$ that is followed by $\operatorname{dvnT}$, a putative ATP-dependent translocator. Within the divercin V41 locus, the proteins deduced from $d \nu n T 2$ and $d \nu n I$ resemble immunity proteins. Considering the $65 \cdot 1 \%$ identity existing between divercin V41 and enterocin A (Aymerich et al., 1996) and the similarity between DvnI and the putative 
enterocin A immunity protein (65\% identity), dvnl is likely to encode the immunity to divercin V41. Thus, the observed genetic organization of the divercin V41 locus may result from the insertion of a DNA fragment that contains $d v n T 1 / T 2$ in-between $d \nu n A$ and $d v n I$. Interestingly, nucleotide sequence analysis revealed the presence of a duplicated degenerate 23-mer sequence within the borders of $d v n T 1 / T 2$, which supports this hypothesis. In addition, genetic rearrangements in bacteriocin loci have been previously suggested according to the presence of IS elements or transposons (Axelsson $\&$ Holck, 1995). Also, the finding within the $d v n l / d v n R$ intergenic region of an ORF lacking transcriptional and translational signals, the deduced protein of which resembles an ATP-dependent translocator, suggests the presence within the divercin V41 locus of an ancestral ABC-transporter and supports the idea of an important DNA rearrangement of the locus. An increasing amount of experimental data suggests that the production of many bacteriocins results from environmental signals (Nes et al., 1996). In most cases, the regulation of bacteriocin production is mediated by a classic twocomponent signal-transducing system constituted by an HPK and an RR. Located within the divercin V41 locus, $d v n K$ and $d v n R$ encode putative HPK and RR, respectively. Comparison of the genetic organization of the genes encoding HPK and RR revealed differences between lantibiotics and non-lantibiotic peptides. Indeed, in anti-Listeria bacteriocin operons, the genes encoding the HPK are located upstream of the genes encoding the RR (Nes et al., 1996), whereas in lantibiotic operons, the HPK genes follow and slightly overlap the $\mathrm{RR}$ genes. Consequently, the putative two-component signal-transducing system of the divercin V41 locus resembles that of lantibiotics although divercin V41 belongs to the non-lantibiotic bacteriocins. This again might reflect important genetic rearrangement of the chromosome of $\mathrm{C}$. divergens $\mathrm{V} 41$, and possibly an ancestral production of a lantibiotic by this strain.

With regard to other class IIa bacteriocins, divercin V41 exhibits some specific features both in the primary structure of the peptide chain and in the genomic organization. Furthermore, with pediocin PA-1 and enterocin $\mathrm{A}$, this is the third example of a class IIa bacteriocin containing two disulphide bonds. These structural and genetic originalities make divercin V41 a good model for structure-function studies on this class of bacteriocins.

\section{REFERENCES}

Axelsson, L. \& Holck, A. (1995). The genes involved in production of and immunity to sakacin A, a bacteriocin from Lactobacillus sake Lb706. J Bacteriol 177, 2125-2137.

Aymerich, T., Holo, H., Håvarstein, L. S., Hugas, M., Garriga, M. \& Nes, I. F. (1996). Biochemical and genetic characterization of enterocin A from Enterococcus faecium, a new anti-listerial bacteriocin in the pediocin family of bacteriocins. Appl Environ Microbiol 62, 1676-1682.

van Belkum, M. J. \& Stiles, M. E. (1995). Molecular charac- terization of genes involved in the production of the bacteriocin leucocin A from Leuconostoc gelidum. Appl Environ Microbiol 61, 3573-3579.

van Belkum, M. J., Kok, J., Venema, G., Holo, H., Nes, I. F., Konings, W. N. \& Abee, T. (1991). The bacteriocin lactococcin A specifically increases permeability of lactococcal cytoplasmic membranes in a voltage-independent, protein-mediated manner. J Bacteriol 173, 7934-7941.

Bhugaloo-Vial, P., Dousset, X., Métivier, A., Sorokine, O., Anglade, P., Boyaval, P. \& Marion, D. (1996). Purification and amino acid sequences of piscicocins V1a and V1b, two class IIa bacteriocins secreted by Carnobacterium piscicola V1 that display significantly different levels of specific inhibitory activity. Appl Environ Microbiol 62, 4410-4416.

Bruno, M. E. C. \& Montville, T. J. (1993). Common mechanistic action of bacteriocins from lactic acid bacteria. Appl Environ Microbiol 59, 3003-3010.

Chikindas, M. J., Garcia-Garcera, M. J., Driessen, A. M., Lederboer, A. M., Nissen-Meyer, J., Nes, I. F., Abee, T., Konings, W. N. \& Venema, G. (1993). Pediocin PA-1, a bacteriocin from Pediococcus acidilactici PAC1.0, forms hydrophilic pores in the cytoplasmic membrane of target cells. Appl Environ Microbiol 59, 3577-3584.

De Man, J. C., Rogosa, M. \& Sharpe, E. (1960). A medium for the cultivation of Lactobacilli. J Appl Bacteriol 23, 130-135.

Diep, D. B., Håvarstein, L. S. \& Nes, I. F. (1996). Characterization of the locus responsible for the bacteriocin production in Lactobacillus plantarum C11. J Bacteriol 178, 4472-4483.

Entian, K. D. \& de Vos, W. M. (1996). Genetics of subtilin and nisin biosynthesis. Antonie Leeuwenhoek 69, 109-117.

Fath, M. J. \& Kolter, R. (1993). ABC transporters: bacterial exporters. Microbiol Rev 57, 995-1017.

Fremaux, C., Héchard, Y. \& Cenatiempo, Y. (1995). Mesentericin Y105 gene clusters in Leuconostoc mesenteroides Y105. Microbiology 141, 1637-1645.

Hanahan, D. (1983). Studies on transformation of Escherichia coli with plasmid DNA. J Mol Biol 166, 557-580.

Hastings, J. W. \& Stiles, M. E. (1991). Antibiosis of Leuconostoc gelidum isolated from meat. J Appl Bacteriol 70, 127-134.

Hastings, J. W., Sailer, M., Johnson, K., Roy, K. L., Vederas, J. C. \& Stiles, M. E. (1991). Characterization of leucocin A-UAL 187 and cloning of the bacteriocin gene from Leuconostoc gelidum. J Bacteriol 173, 7491-7500.

Håvarstein, L. S., Holo, H. \& Nes, I. F. (1994). The leader peptide of colicin $\mathrm{V}$ shares consensus sequences with leader peptides that are common amongst peptide bacteriocins produced by Grampositive bacteria. Microbiology 140, 2383-2389.

Héchard, Y., Derijard, B., Letellier, F. \& Cenatiempo, Y. (1992). Characterization and purification of mesentericin $Y 105$, an antiListeria bacteriocin from Leuconostoc mesenteroides. J Gen Microbiol 138, 2725-2731.

von Heijne, G. (1990). The signal peptide. J Membr Biol 115, 195-201.

Higgins, C. F., Hiles, I. D., Salmond, G. P. 87 other authors (1986). A family of related ATP-binding subunits coupled to many distinct biological processes in bacteria. Nature 323, 448-450.

Hoch, J. A. \& Silhavy, T. J. (editors) (1995). Two-Component Signal Transduction. Washington, DC: American Society for Microbiology.

Holck, A., Axelsson, L., Birkeland, S. E., Aukrust, T. \& Blom, H. (1992). Purification and amino acid sequence of sakacin $A$, a 
bacteriocin from Lactobacillus sake Lb706. J Gen Microbiol 138, $2715-2720$.

Huhne, K., Axelsson, L., Holck, A. \& Krockel, L. (1996). Analysis of the sakacin P gene cluster from Lactobacillus sake Lb674 and its expression in sakacin-negative Lb. sake strains. Microbiology 142, 1437-1448.

Jack, R. W., Tagg, J. R. \& Ray, B. (1995). Bacteriocins of grampositive bacteria. Microbiol Rev 59, 171-200.

Jaquinod, M., Potier, N., Klarskov, K. \& 7 other authors (1993). Sequence of pig lens aldose reductase and electrospray mass spectrometry of non-covalent and covalent complexes. Eur $J$ Biochem 218, 893-903.

Jimenez-Diaz, R., Rios-Sanchez, R. M., Desmazeaud, M., RuizBarba, J. L. \& Piard, J.-C. (1993). Plantaricin S and T, two new bacteriocins produced by Lactobacillus plantarum LPC010 isolated from a green olive fermentation. Appl Environ Microbiol 59, 1416-1424.

Klaenhammer, T. R. (1993). Genetics of bacteriocins produced by lactic acid bacteria. FEMS Microbiol Rev 12, 39-85.

Marugg, J. D., Gonzales, C. F., Kunka, B. S., Ledeboer, A. M., Pucci, M. J., Toonen, M. Y., Walker, S. A., Zoetmulder, L. C. M. \& Vandenbergh, P. A. (1992). Cloning, expression and nucleotide sequence of genes involved in production of pediocin PA-1, a bacteriocin from Pediococcus acidilactici PAC1.0. Appl Environ Microbiol 58, 2360-2367.

Muriana, P. M. \& Klaenhammer, T. R. (1987). Conjugal transfer of plasmid-encoded determinants for bacteriocin production and immunity in Lactobacillus acidophilus. Appl Environ Microbiol 53, 553-560.

Muriana, P. M. \& Klaenhammer, T. R. (1991). Purification and partial characterization of lactacin $\mathrm{F}$, a bacteriocin produced by Lactobacillus acidophilus 11088. Appl Environ Microbiol 57, 114-121.

Nes, I. F., Diep, D. B., Håvarstein, L. S., Brurberg, M. B., Eijsink, V. \& Holo, H. (1996). Biosynthesis of bacteriocins in lactic acid bacteria. Antonie Leeuwenhoek 70, 113-128.

Piard, J.-C., Muriana, P. M., Desmazeaud, M. \& Klaenhammer, T. R. (1992). Purification and partial characterization of lacticin 481, a lanthionine containing bacteriocin produced by Lactococcus lactis subsp. lactis CNRZ 481. Appl Environ Microbiol 58, 279-284.

Pilet, M.-F., Dousset, X., Barre, R., Novel, G., Desmazeaud, M. \& Piard, J.-C. (1995). Evidence of two bacteriocins produced by
Carnobacterium piscicola and Carnobacterium divergens isolated from fish and active against Listeria monocytogenes. J Food Prot 58, 256-262.

Quadri, L. E. N., Sailer, M., Roy, K. L., Vederas, J. C. \& Stiles, M. E. (1994). Chemical and genetic characterization of bacteriocins produced by Carnobacterium piscicola LV17 B. J Biol Chem 269, 12204-12211.

Sambrook, J., Fritsch, E. F. \& Maniatis, T. (1989). Molecular Cloning: a Laboratory Manual, 2nd edn. Cold Spring Harbor, NY: Cold Spring Harbor Laboratory.

Sanger, F., Nicklen, S. \& Coulson, R. (1977). DNA sequencing with chain-terminating inhibitors. Proc Natl Acad Sci USA 74, 5463-5467.

Schillinger, U., Geisen, R. \& Holzapfel, W. H. (1996). Potential of antagonistic microorganisms and bacteriocins for the biological preservation of foods. Trends Food Sci Tech 7, 158-164.

Scopes, R. K. (1988). Protein Purification. Principles and Practice. New York: Springer.

Stoddard, G. W., Petzel, J. P., van Belkum, M. J., Kok, J. \& McKay, L. L. (1992). Molecular analyses of the lactococcin A gene cluster from Lactococcus lactis subsp. lactis biovar diacetylactis WM4. Appl Environ Microbiol 58, 1952-1961.

Tichaczek, P. S., Nissen-Meyer, J., Nes, I. F., Vogel, R. F. \& Hammes, W. P. (1992). Characterization of the bacteriocins curvacin A from Lactobacillus curvatus LTH1174 and sakacin P from Lactobacillus sake LTH673. Syst Appl Microbiol 15, $460-468$.

Venema, K., Kok, J., Marugg, J. D., Toonen, M. Y., Ledeboer, A. M., Venema, G. \& Chikindas, M. L. (1995). Functional analysis of the pediocin operon of Pediococcus acidilactici PAC1.0: PedB is the immunity protein and PedD is the precursor processing enzyme. Mol Microbiol 17, 515-522.

de Vos, W. M., Kuipers, O. P., van der Meer, J. R. \& Siezen, R. J. (1995). Maturation pathway of nisin and other lantibiotics: posttranslationally modified antimicrobial peptides exported by gram-positive bacteria. Mol Microbiol 17, 427-437.

Worobo, R. W., van Belkum, M. J., Sailer, M., Roy, K. L., Vederas, J. C. \& Stiles, M. E. (1995). A signal peptide secretion-dependent bacteriocin from Carnobacterium divergens. J Bacteriol 177, 3143-3149.

Received 2 March 1998; revised 15 June 1998; accepted 22 June 1998. 